\title{
Insulin and/or dexamethasone regulation of lactate production and its relationship to glucose utilization by ovine and bovine adipose tissue explants incubated for 7 days
}

\author{
Y Faulconnier, A Ferlay, Y Chilliard * \\ Laboratoire sous-nutrition des ruminants, Inra, Theix, 63122 Saint-Genès-Champanelle, France
}

(Received 19 December 1996; accepted 20 April 1997)

\begin{abstract}
Summary - This study investigated the hormonal regulation of lactate production and the lactate production/glucose utilization ratio in sheep and cow adipose tissue (AT) explants. The effects of insulin $(2 \mathrm{mU} / \mathrm{mL})$ and/or dexamethasone (DEX, $100 \mathrm{nM})$ were measured in perirenal AT of adult nonlactating non-pregnant cows $(n=5)$ or ewes $(n=5)$ given a restricted diet followed by overfeeding. The AT explants were incubated for 7 days. Under basal conditions, the lactate production was two times greater in sheep than in cow AT. Insulin increased lactate production in the two species, whereas DEX decreased it. DEX, in the presence of insulin, increased lactate production from day 3 to day 7. The lactate production/glucose utilization ratio was about two times greater in sheep than in cow AT. The presence of insulin increased, and that of DEX decreased this ratio in sheep AT, whereas it was not changed in cow AT. DEX, in the presence of insulin, increased this ratio in the two species after 4 or 5 days.
\end{abstract}

ruminant / adipose tissue / lactate / insulin / dexamethasone

Résumé - Effets de l'insuline et/ou de la dexaméthasone sur la production de lactate et son rapport avec l'utilisation de glucose par les tissus adipeux ovin et bovin maintenus en culture pendant 7 jours. La régulation hormonale de la production de lactate et du rapport production de lactate/utilisation de glucose dans le TA est étudiée chez les ovins et les bovins. Les effets de l'insuline ( $2 \mathrm{mUI} / \mathrm{mL}$ ) et/ou de la DEX $(100 \mathrm{nM})$ sont mesurés sur du TA périrénal provenant de cinq vaches et de cinq brebis adultes, taries et non gravides, sous-nutries puis réalimentées. Les explants de TA sont cultivés pendant 7 jours. Dans les conditions basales, la production de lactate est deux fois plus importante avec le TA ovin qu'avec le TA bovin. L'insuline augmente la production de lactate chez les deux espèces alors que la DEX la diminue. L'addition de DEX dans un milieu supplémenté en insu-

* Correspondence and reprints

Tel: (33) 04736241 14; fax: (33) 04736245 19; e-mail: chilliar@clermont.inra.fr 
line n'a d'effet qu'à partir du $3^{\mathrm{e}}$ jour de culture. Par ailleurs, le rapport production de lactate/utilisation de glucose est environ deux fois plus important chez la brebis que chez la vache. L'insuline augmente et la DEX diminue ce rapport dans le TA ovin mais pas dans le TA bovin. La DEX en présence d'insuline augmente ce rapport chez les deux espèces après 4 ou 5 jours de culture.

ruminant / tissu adipeux / lactate / insuline / dexaméthasone

\section{INTRODUCTION}

While numerous metabolic similarities exist between sheep and cow adipose tissue (AT), Chilliard and Faulconnier (1995) have documented differences in the effects of adding insulin and/or dexamethasone (DEX) on glucose utilization between cow and sheep perirenal AT explants incubated for 7 days. Indeed, the effect of insulin was greater in cow than in sheep AT on the first day of incubation, then the relationship was reversed from day 4 . Moreover, the addition of DEX to the insulin-supplemented medium significantly increased glucose utilization in sheep AT, whereas it had no effect in cow AT. Smith and Prior (1986) also noted pronounced differences in glucose utilization between sheep and cow subcutaneous AT, depending on the presence or absence of acetate and lactate in the incubation medium. The products of glucose metabolism in ruminant AT are carbon dioxide, NADPH and acylglycerol glycerol (Vernon, 1980), but glucose is also recycled as lactate both in vivo (Khachadurian et al, 1966) and in vitro (Khachadurian et al, 1967; Robertson et al, 1982). In order to better understand the metabolic significance of the differences in glucose utilization between cow and sheep AT, additional measurements were carried out comparing the effects of insulin and/or DEX on lactate production and lactate production/glucose utilization ratio ( $\mathrm{LP} / \mathrm{GU}$ ) in the $\mathrm{AT}$ of these two species.

\section{MATERIALS AND METHODS}

\section{Animals and diets}

Adult non-lactating non-pregnant Holstein cows ( $n=5,7-9$ years old) and ewes of the synthetic INRA-401 breed (Romanov $\times$ Berrichon du Cher) $(n=5,4-6$ years old) after their third to fifth lactation were used. They were fed for 8 (ewes) and 10 (cows) days a restricted diet (that provided 20 and $22 \%$ of the estimated metabolizable energy requirement for maintenance for ewes and cows, respectively; Inra, 1989) of straw $(1 \mathrm{~kg} /$ day) and hay $(1.5 \mathrm{~kg} /$ day $)$ for cows or straw only (400 to $500 \mathrm{~g} /$ day) for ewes. Then they were overfed for 10 (ewes) and 21 (cows) days before slaughter, with ad libitum access to hay and water plus defined amounts of concentrate. The composition and distribution of concentrate mix for the cows (Faulconnier et al, 1994) and the ewes (Chilliard and Faulconnier, 1995) have been described previously. The voluntary intake was 188 and $228 \%$ of the metabolizable energy requirement for maintenance for cows and ewes, respectively. Cows were killed with a captivebolt humane killer and ewes were exsanguinated. After death, samples of perirenal AT were excised aseptically and immediately placed into an incubator vessel containing sterile Hank's buffer (Gibco/BRL, France), pH 7.4 at $37^{\circ} \mathrm{C}$.

\section{Adipose tissue incubation}

The samples of perirenal AT were finely cut (10-15 mg pieces), transferred to plastic flasks and placed in an incubator at $37^{\circ} \mathrm{C}$ with an atmosphere of $95 \% \mathrm{O}_{2} / 5 \% \mathrm{CO}_{2}(\mathrm{v} / \mathrm{v})$. The AT explants (1-1.5 g) were incubated in sterile Medium 199 $(30 \mathrm{~mL})$ containing Earles salts, L-glutamine and 25 mM HEPES (pH 7.5; Gibco/BRL, France) supplemented with $7 \mathrm{mM}$ acetate (final concen- 
tration $7.6 \mathrm{mM}$ ), antibiotics and hormones as described previously (Faulconnier et al, 1994; Chilliard and Faulconnier, 1995). The AT explants were incubated for 7 days. For each animal, AT explants were incubated in duplicate for each kind of medium (eg, control without added hormones, insulin ( $2 \mathrm{mU} / \mathrm{mL})$, DEX (100 $\mathrm{nM})$, insulin $(2 \mathrm{mU} / \mathrm{mL})$ plus DEX $(100 \mathrm{nM})$ ) and for each incubation time (from day 1 to day 7). The incubation medium was replaced with fresh medium once daily. Samples of each medium were retained after each 24-h incubation and stored at $-20^{\circ} \mathrm{C}$ until their lactate content was quantified.

\section{Assay of lactate, and expression of results}

The amount of lactate released into the incubation medium was determined by measuring lactate concentration at the beginning and end of each 24-h incubation period for 7 days. The lactate concentration was assayed on $8 \mu \mathrm{L}$ of culture medium, with lactate oxidase (Shimojo et al, 1989) using a multianalyser (Elan, MerckClévenot, Nogent-sur-Marne, France) and a commercial kit (BioMérieux, France, reference no 61192). Repeatability and sensitivity of the lactate measurement were evaluated. Standard solutions at $25,40,100,200,400,1000,2000$ and $4000 \mu \mathrm{M}$ were successively analysed with five repetitions at each concentration. The SD were, respectively, 3.6, 2.2, 4.1, 3.9, 5.3, 2.6, 14.4 and $20.9 \mu \mathrm{M}$, corresponding to coefficients of variation of 11.3, 4.5, 3.4, 1.6, 1.1, 0.2 and $0.7 \%$, respectively. The lower limit of detection was calculated to be $14 \mu \mathrm{M}$. The range of lactate concentration values in the culture media from our study was $200-4000 \mu \mathrm{M}$. The glucose concentration remaining at the end of each incubation period was always higher than $45 \mu \mathrm{mol}$ per well (ie, $1.5 \mathrm{mM}$ ), and thus was not limiting for lactate production. The number of adipocytes per gram of AT was determined previously. The mean cell diameter at day 0 was $122 \pm 1 \mu \mathrm{m}$ in cow and $111 \pm 4 \mu \mathrm{m}$ in sheep AT (Faulconnier et al, 1996). Lactate production was expressed in micromoles of lactate released into the incubation medium $/ 24 \mathrm{~h} / 10^{6}$ adipocytes. The amount of glucose removed daily from the incubation medium by the same AT explants was from data of Chilliard and Faulconnier (1995). The LP/GU was expressed as the ratio of lactate carbons appearing in the medium compared to the glucose carbons disappearing from the medium, expressed in percent.

\section{Statistical analysis}

Data from both species and all incubation times were analyzed together using the GLM procedures of SAS (1987) (table I). The model included the effects of species (a), individual within species (b), insulin (c), DEX (d), insulin $\times$

Table I. Analysis of changes in lactate production (fig 1), and lactate production/glucose utilization ratio (LP/GU, fig 2) by sheep and cow adipose tissue explants incubated for 7 days.

\begin{tabular}{|c|c|c|c|c|c|c|c|c|c|c|c|c|}
\hline \multirow[b]{2}{*}{ Item } & \multicolumn{12}{|c|}{$\begin{array}{l}\text { Effects } \\
(\mathrm{P}<)\end{array}$} \\
\hline & $S^{\mathrm{a}}$ & $I^{\mathrm{b}}$ & $D E X^{\mathrm{c}}$ & $\begin{array}{c}I X \\
D E X^{\mathrm{d}}\end{array}$ & $S \times I^{\mathrm{e}}$ & $\begin{array}{c}S \times \\
D E X^{\mathrm{f}}\end{array}$ & $\begin{array}{l}S \times I X \\
D E X^{\mathrm{g}}\end{array}$ & $d^{\mathrm{h}}$ & $I \times d^{\mathrm{i}}$ & $\begin{array}{c}D E X \\
x d^{\mathrm{j}}\end{array}$ & $\begin{array}{l}S \times I \\
x d^{\mathrm{k}}\end{array}$ & $\begin{array}{c}I \times D E X \\
\quad \times d^{l}\end{array}$ \\
\hline $\begin{array}{l}\text { Lactate } \\
\text { production }\end{array}$ & 0.001 & 0.001 & 0.06 & 0.001 & 0.001 & 0.26 & 0.002 & 0.001 & 0.001 & 0.001 & 0.001 & 0.001 \\
\hline LP/GU & 0.10 & 0.40 & 0.62 & 0.05 & 0.58 & 0.77 & 0.47 & 0.002 & 0.81 & 0.99 & 0.99 & 0.08 \\
\hline
\end{tabular}

${ }^{\mathrm{a}} \mathrm{S}=$ species; ${ }^{\mathrm{b}} \mathrm{I}=$ insulin; ${ }^{\mathrm{c}} \mathrm{DEX}=$ dexamethasone; ${ }^{\mathrm{d}} \mathrm{I} \times \mathrm{DEX}=$ insulin $\times$ dexamethasone interaction; ${ }^{\mathrm{e}} \mathrm{S} \times \mathrm{I}=$ species $\times$ insulin interaction; ${ }^{f} \mathrm{~S} \times \mathrm{DEX}=$ species $\times$ dexamethasone interaction; ${ }^{\mathrm{g}} \mathrm{S} \times \mathrm{I} \times \mathrm{DEX}=$ species $\times$ insulin $\times$ dexamethasone interaction; ${ }^{\mathrm{h}} \mathrm{d}=$ day $(1$ to 7$) ;{ }^{\mathrm{i}} \mathrm{I} \times \mathrm{d}=$ insulin $\times$ day interaction; ${ }^{\mathrm{j}} \mathrm{DEX} \times \mathrm{d}=$ dexamethasone $\times$ day interaction; ${ }^{k} \mathrm{~S} \times \mathrm{I} \times \mathrm{d}=$ species $\times$ insulin $\times$ day interaction; ${ }^{\prime} \mathrm{I} \times \mathrm{DEX} \times \mathrm{d}=$ insulin $\times$ dexamethasone $\times$ day interaction. 
DEX (e), species $\times$ insulin (f), species $\times$ DEX $(g)$, species $\times$ insulin $\times$ DEX (h), within animal profile of hormonal treatment (i), day of incubation (j), species $\times$ day $(k)$, insulin $\times$ day (l), DEX $\times$ day $(m)$, species $\times$ insulin $\times$ day $(n)$, species $\times$ DEX $\times$ day (o), insulin $\times$ DEX $\times$ day $(p)$, and species $\times$ insulin $\times$ DEX $\times$ day $(q)$. The effect of (b) was used as the error term for the factor (a) (between animal variation). The effect of (i) was used as the error term for the factors (c) to (h) (within animal, between hormonal treatment variation). The residual error for the model was used as the error term for the factors (j) to (q) (within animal, within hormonal treatment variation). The species $\times$ DEX $\times$ day interaction was not significant $(P>0.12)$, so it is not presented in the results.

When there was a significant day effect or interactions involving day, their sums of squares were partitioned (Winer, 1971) into sums of squares for polynomial (ie, linear, quadratic and cubic) contrasts (table II). For example, a "species $x$ day' significant linear contrast expresses the effect of fitting two different linear relationships, one for each level of the factor 'species', instead of a single overall linear contrast.

Table II. Polynomial contrasts for the effects of incubation time and interactions with other factors ${ }^{\mathrm{a}}$.

\begin{tabular}{lcccc}
\hline & \multicolumn{5}{c}{$\begin{array}{c}\text { Effects } \\
(\mathrm{P}<)\end{array}$} \\
\cline { 2 - 5 } Item & $d^{\mathrm{b}}$ & $I \times d^{\mathrm{c}}$ & $\begin{array}{c}D E X \\
\times d^{\mathrm{d}}\end{array}$ & $\begin{array}{c}S \times I \\
\times d^{\mathrm{e}}\end{array}$ \\
\hline Lactate & & & & \\
Linear & 0.29 & 0.001 & 0.001 & 0.06 \\
Quadratic & 0.001 & 0.001 & 0.69 & 0.001 \\
Cubic & 0.001 & 0.001 & 0.56 & 0.04 \\
LP/GU & & & & \\
Linear & 0.001 & 0.57 & 0.72 & 0.97 \\
Quadratic & 0.48 & 0.18 & 0.77 & 0.96 \\
Cubic & 0.06 & 0.59 & 0.79 & 0.73 \\
\hline
\end{tabular}

${ }^{a}$ Data from figure 1 for lactate production and from figure 2 for lactate production/glucose utilization ratio $(\mathrm{LP} / \mathrm{GU}) ;{ }^{\mathrm{b}} \mathrm{d}=$ day $(\mathrm{l}$ to 7$) ;{ }^{\mathrm{c}} \mathrm{I} \times \mathrm{d}=$ insulin $\times$ day interaction; ${ }^{\mathrm{d}} \mathrm{DEX} \times \mathrm{d}=$ dexamethasone $\times$ day interaction; ${ }^{\mathrm{e}} \mathrm{S} \times \mathrm{I} \times \mathrm{d}=$ species $\times$ insulin $\times$ day interaction.
Data presented in figures 1 and 2 were also analyzed for each species and each incubation time with the GLM procedures of SAS (1987) according to a mathematical model taking the animal effect into account, and comparing the four treatments (control, insulin, DEX, and insulin + DEX). The differences between treatments were tested using the Student-NewmanKeuls test with a probability of $0.10,0.05$ or 0.01 .

The differences between two days of incubation were tested using the paired $t$-test (Snedecor and Cochran, 1967) with a probability of 0.05 or 0.01 .

\section{RESULTS}

\section{Overall analysis}

For lactate production, the main effects of species, insulin, DEX and day of incubation were significant, as were several interactions: insulin $\times$ DEX, species $\times$ insulin, species $\times$ insulin $\times$ DEX, species $\times$ day, insulin $\times$ day, DEX $\times$ day, species $\times$ insulin $x$ day, insulin $\times$ DEX $\times$ day and species $\times$ insulin $\times$ DEX $\times$ day (table I). The effect of day of incubation on lactate production was complex, with significant quadratic and cubic terms. Moreover, the linear, quadratic and cubic terms were changed significantly by interactions with insulin or with species $x$ insulin. The linear effect of day also was changed significantly by interactions with DEX (table II).

For LP/GU, the day of incubation was significant, as were insulin $\times$ DEX and insulin $\times$ DEX $\times$ day of incubation interactions (table I). The effect of day was linear and cubic (table II).

\section{Lactate production by adipose tissue explants}

Under basal conditions, lactate production in sheep AT $\left(18.5 \pm 5.0 \mu \mathrm{mol} / 24 \mathrm{~h} / 10^{6}\right.$ adipocytes) was approximately two times 
greater $(P<0.01)$ than in cow AT $(7.9 \pm$ $3.5 \mu \mathrm{mol} / 24 \mathrm{~h} / 10^{6}$ adipocytes), whatever the incubation period. Moreover, in cow AT, lactate production was higher $(P<0.01)$ on day 3 of incubation than on day 1 . After this time, the lactate production decreased until day 7 of incubation ( 24.2 and 11.5 $\mu \mathrm{mol} / 24 \mathrm{~h} / 10^{6}$ adipocytes on day 2 and 7 , $P<0.01$, in sheep AT and 13.3 and $3.0 \mu \mathrm{mol} / 24 \mathrm{~h} / 10^{6}$ adipocytes on day 3 and $7, P<0.1$, in cow AT, respectively; fig 1 ).

The addition of $2 \mathrm{mU} / \mathrm{mL}$ of insulin to the incubation medium increased $(P<0.001)$ lactate production in sheep and cow AT explants (table I). However, the effect of insulin in the two species differed $(P<0.001)$ with incubation time (insulin $x$ day of incubation; table I). Indeed, insulin increased lactate production on day 1 of incubation $(+56$ and $+52 \%$, in cow and sheep AT, respectively) but more markedly on day 2 of incubation $(+89$ and $+126 \%$; on day 2 in cow and sheep AT, respectively; fig 1). Moreover, lactate production in the medium supplemented with insulin increased $(P<0.05$ or $P<0.01$ in cows and ewes, respectively) from day 1 to day 2 for the two species, but then it decreased $(P<0.01)$ from day 2 to day $7(21.1$ and $7.9 \mu \mathrm{mol} / 24 \mathrm{~h} / 10^{6}$ adipocytes on days 2 and 7 in cow AT and 54.6 and $25.1 \mu \mathrm{mol} / 24 \mathrm{~h} / 10^{6}$ adipocytes on days 2 and 7 in sheep AT, respectively; fig 1).

The addition of DEX (100 nM) to the incubation medium decreased $(P<0.06$; table I) lactate production but differently according to the species (fig 1). In ovine $\mathrm{AT}$, the addition of DEX alone to the incubation medium decreased $(-68 \%, P<0.05)$ lactate production during the first 5 days of

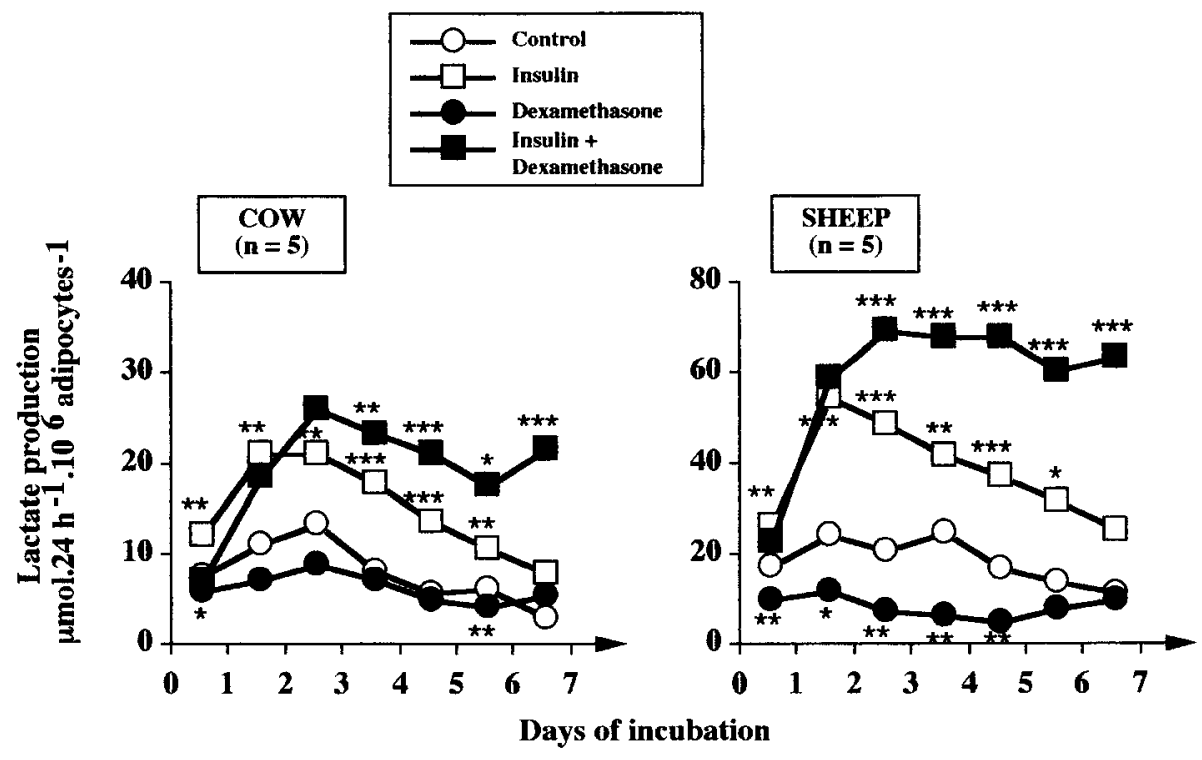

Fig 1. Effects of insulin ( $2 \mathrm{mU} / \mathrm{mL}$ ) and/or dexamethasone (DEX, $100 \mathrm{nM}$ ) on lactate production by cow and sheep adipose tissue explants. Effects of insulin $(\square)$ or DEX $(-)$ were tested against incubation without added hormone (control, $\bigcirc$ ). Effect of DEX addition to the insulin-supplemented medium ( $)$ was tested against incubation with insulin alone $(\square)$. Pooled within treatment SEM for days 1 to 7 were $3.8,3.3,3.7,2.7,1.6,3.0$ and 2.4 in cows and 2.7, 4.4, 4.4, 4.8, 4.8, 5.8 and 5.9 in ewes, respectively. ${ }^{* * *}, * *$ or $* P<0.01,0.05$ or 0.1 , respectively. 
incubation, whereas the effect was less marked ( $-23 \%$, and not significant) in cow AT during the same period (fig 1).

The effect of the DEX addition to the insulin-supplemented medium on lactate production changed $(P<0.001)$ with incubation time (insulin $\times$ DEX $\times$ day of incubation; table I). The addition of DEX to the insulin-supplemented medium did not change lactate production on the first 2 (sheep AT) or 3 (cow AT) days of incubation, but it increased $(P<0.01$ or $P<0.05)$ this production from day $3(+42 \%$ for ewes) or $4(+31 \%$ for cows) to $7(+154$ and + $172 \%$ for ewes and cows, respectively) (fig 1). Moreover, lactate production in the medium supplemented with insulin plus DEX increased $(P<0.01)$ from days 1 to 3 for the two species, but then remained unchanged from days 3 to 7 (fig 1).

\section{Lactate production/glucose utilization ratio in adipose tissue explants}

The LP/GU in sheep AT $(40,45$ and $52 \%$ in basal conditions, in the presence of insulin and in the presence of insulin plus DEX, respectively) was approximately two times greater than the LP/GU in cow AT $(20,23$ and $34 \%$, respectively).

The addition of insulin alone to the medium increased $(P<0.01$, on days 2 and $3)$ and the addition of DEX alone decreased $(P<0.01$, on days 3 and 5$) \mathrm{LP} / \mathrm{GU}$ in sheep AT (fig 2). However, these two hormones had no significant effects in cow AT (fig 2).

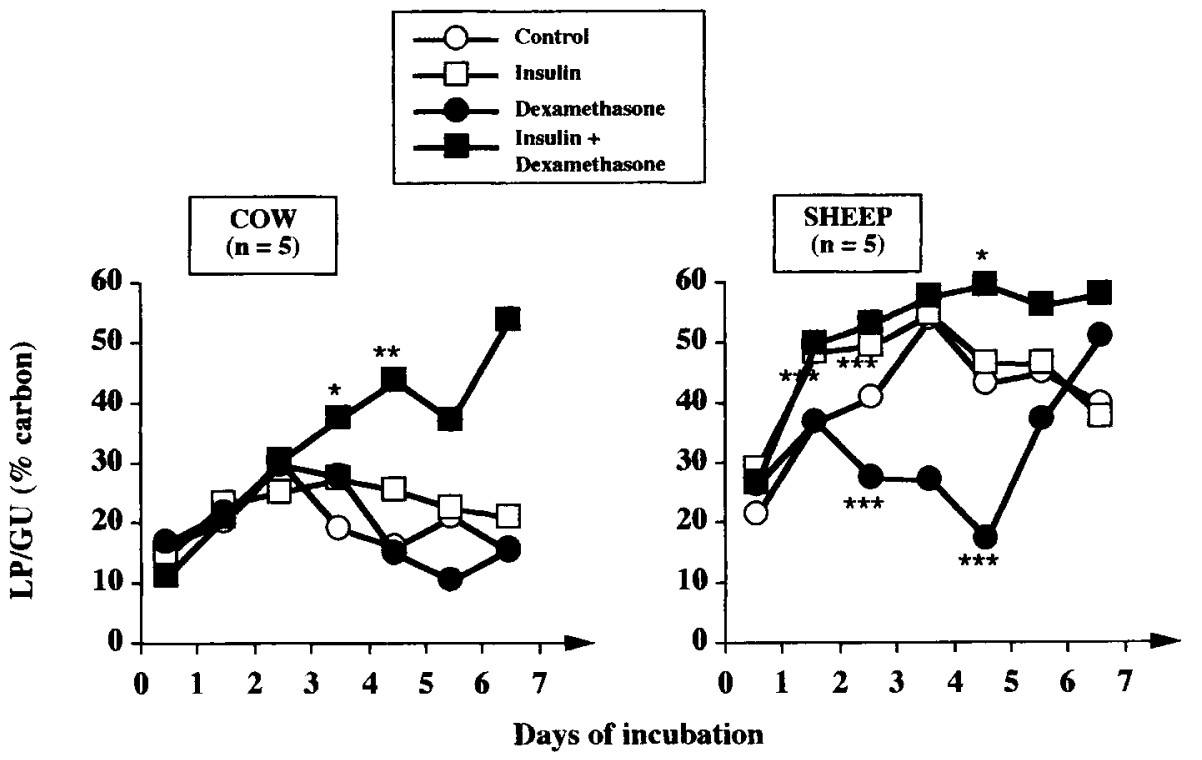

Fig 2. Effects of insulin ( $2 \mathrm{mU} / \mathrm{mL})$ and/or dexamethasone (DEX, $100 \mathrm{nM}$ ) on lactate production/glucose utilization ratio (LP/GU, \% carbon) by cow and sheep adipose tissue explants. Effects of insulin $(\square)$ or DEX $(\odot)$ were tested against incubation without added hormone (control, $\bigcirc$ ). Effect of DEX addition to the insulin-supplemented medium ( $\square$ ) was tested against incubation with insulin alone $(\square)$. Pooled within treatment SEM for day 1 to 7 were $1.1,0.6,1.1,3.3,6.0,4.8$ and 8.3 in cows and $1.4,3.2,5.1,6.4,7.9,3.5$ and 4.3 in ewes, respectively. $* * *, * *$ or $* P<0.01,0.05$ or 0.1 respectively. 
The effect of DEX addition to the insulinsupplemented medium differed $(P<0.08)$ with incubation time (insulin $\times \mathrm{DEX} \times$ day of incubation, table I). The addition of DEX to the insulin-supplemented medium had no significant effect on LP/GU during the first 3 (cow AT) or 4 (sheep AT) days of incubation, but then it increased LP/GU at day 4 and day 5 (cow AT) or at day 5 (sheep AT) (fig 2). Moreover, this effect was greater in cow AT $(+69 \%$, on day 5$)$ than in sheep AT ( $+19 \%$, on day 5 ) (fig 2 ).

\section{DISCUSSION}

Although acetate is the major source of carbon for fatty acid synthesis in ruminant AT, this tissue uses glucose to produce NADPH by partial oxidation via the pentose phosphate cycle followed by the production of ribose-5-phosphate for nucleic acids synthesis. In addition, glucose also contributes, with lactate, to glyceride-glycerol synthesis (Vernon, 1980; Smith and Prior, 1982). However, the major products of glucose metabolism in ruminant $\mathrm{AT}$ are lactate and carbon dioxide, especially in the presence of high acetate concentration in the incubation medium (Smith and Prior, 1986). Some lactate could be produced in AT from endogenous glycogen or through gluconeogenesis from amino acids, but this has not been studied in ruminant AT. However, when no lactate is added to the incubation medium (as in our study), most of the lactate produced is derived from exogenous glucose (Smith, 1983). Smith (1983) and Smith and Prior (1986) demonstrated that glucose utilization is dependent upon overall rate of lipogenesis from acetate. Although we did not measure lipogenesis from acetate in our study, glucose utilization was closely related to acetate utilization (table III), and the slope of the regression was significantly $(P<0.001)$ higher in sheep than in cow AT, indicating a higher glucose utilization in sheep AT for the same acetate utilization.
Table III. Relationships between lactate production and glucose and acetate utilization.

\begin{tabular}{cc}
$\operatorname{Cow}(\mathrm{n}=60)$ & Sheep $(\mathrm{n}=60)$ \\
\hline Glucose $=0.32$ acetate +4.6 & Glucose $=0.49$ acetate +7.1 \\
$r=0.63$ & $r=0.74$ \\
Lactate $=0.31$ acetate -7.4 & Lactate $=0.59$ acetate -1.9 \\
$r=0.34$ & $r=0.62$ \\
Lactate $=0.68$ glucose -5.1 & Lactate $=1.16$ glucose -9.0 \\
$r=0.66$ & $r=0.87$ \\
\hline
\end{tabular}

Lactate production (present study) and glucose or acetate utilization (Chilliard and Faulconnier, 1995) were determined ( $\mu$ moles $/ 24 \mathrm{~h} / 10^{6}$ adipocytes) for days $1+2,3+4$, and $5+6+7$. Regression equations are those of the principal axis. All coefficients of correlation were significant $(P<0.01)$.

Lactate production was related to both acetate and glucose utilization (table III), but more closely to glucose than to acetate utilization. Again, lactate production was significantly $(P<0.001)$ higher in sheep than in cow AT, for the same acetate or glucose utilization.

Under basal conditions, lactate production at day 1 was two times greater with sheep $\left(17.5 \mu \mathrm{mol} / 24 \mathrm{~h} / 10^{6}\right.$ adipocytes $)$ than with cow $\left(7.8 \mu \mathrm{mol} / 24 \mathrm{~h} / 10^{6}\right.$ adipocytes $)$ AT. These results are consistent with the greater glucose utilization by sheep ( $40.4 \mu \mathrm{mol} / 24 \mathrm{~h} / 10^{6}$ adipocytes) than by cow $\left(23.5 \mu \mathrm{mol} / 24 \mathrm{~h} / 10^{6}\right.$ adipocytes) AT, on day 1 of incubation, using the same experimental conditions and AT explants (Chilliard and Faulconnier, 1995). Similarly, after extended incubation, lactate production was two times greater with sheep ( $18.6 \mu \mathrm{mol} / 24 \mathrm{~h} / 10^{6}$ adipocytes) than with cow $\left(7.9 \mu \mathrm{mol} / 24 \mathrm{~h} / 10^{6}\right.$ adipocytes $) \mathrm{AT}$, whereas glucose utilization was similar in the two species $\left(21.7\right.$ and $18.5 \mu \mathrm{mol} / 24 \mathrm{~h} / 10^{6}$ adipocytes in sheep and cow $\mathrm{AT}$, respectively) (Chilliard and Faulconnier, 1995). As a consequence, at day 1 , the LP/GU in cow $(16.6 \%)$ and sheep $(21.6 \%)$ AT were similar, but they differed after extended incubation. These results agree with those of 
Plested et al (1987) who reported that lactate release amounted to $25 \%$ of glucose utilization by subcutaneous sheep AT explants incubated for $24 \mathrm{~h}$. To our knowledge, the only study comparing directly LP/GU between sheep and cow AT was that of Smith and Prior (1986) with subcutaneous AT incubated for $3 \mathrm{~h}$. They reported that the specific yield of lactate from glucose was $30-32 \%$ in AT of both species in the presence of $10 \mathrm{mM}$ acetate plus $10 \mathrm{mM}$ lactate. Thus, there was no difference between species after $3 \mathrm{~h}$ of incubation as in our study after 1 day of incubation. However, their values $(30-32 \%)$ are higher than those of our study (17-21\%). This difference might be due to difference in incubation duration and/or to the fact that all the flasks in their study contained high lactate $(10 \mathrm{mM})$ and insulin $(33 \mathrm{mU} / \mathrm{mL})$ concentrations. We can speculate that, in the present study, the cow AT used more glucose carbons in the tricarboxylic acid cycle, or for nucleic acid synthesis via the pentose-phosphate cycle, and/or for glyceride-glycerol synthesis. Indeed, these two latter pathways could be related to glucose-6-phosphate dehydrogenase (Faulconnier et al, 1996) and glycerol3-phosphate dehydrogenase (Chilliard et al, 1991; Sebastian et al, 1993 ) activities that were greater in cow than in sheep visceral AT. However, glucose-6-phosphate dehydrogenase activity was similar in cow and sheep subcutaneous AT (Smith and Prior, 1986). In rat AT, 5 to $60 \%$ of glucose carbons were converted to lactate depending on the age of the animal (Grandall et al, 1983; Thacker et al, 1987), its nutritional state (Thacker et al, 1987; Newby et al, 1990) and the adipose storage site (Fried et al, 1982; Newby et al, 1988). The LP/GU was all the higher as the de novo lipogenesis from glucose was low. This agrees with the high LP/GU observed in cows and especially in ewes, since de novo lipogenesis from glucose is low in ruminant AT. The higher LP/GU in sheep AT from day 2 of incubation may be related to its higher uti- lization of glucose, relative to acetate (table III), thus allowing a higher percentage of recycling of glucose carbons to lactate.

Insulin $(2 \mathrm{mU} / \mathrm{mL})$ increased lactate production in sheep and cow AT explants whatever the duration of incubation. This is consistent with the fact that insulin also stimulated glucose utilization by cow and sheep AT under the same experimental conditions (Chilliard and Faulconnier, 1995). The magnitude of the increase $(+52$ and + $56 \%$ in sheep and cow AT, respectively) after $24 \mathrm{~h}$ in vitro was similar to that observed by Vernon and Taylor (1988) with ovine subcutaneous AT. Similar results were also noted with isolated rat adipocytes incubated for $2 \mathrm{~h}$ (Fried et al, 1982). Moreover, in the present study, insulin produced a more marked stimulation of lactate production on day 2 than on day 1 of incubation, which is in agreement with Plested et al (1987) with sheep subcutaneous AT explants. We also observed that the basal LP/GU in sheep AT was increased by insulin on day $1(+34 \%$, not significant), day $2(+30 \%, P<0.01)$ and day $3(+22 \%, P<0.01)$ of the incubation, whereas insulin had no effect on LP/GU in cow AT. These results are contrary to those of Vernon and Taylor (1988), who reported that insulin $(2.5 \mathrm{mU} / \mathrm{mL})$ decreased $(-22 \%)$ LP/GU in sheep subcutaneous AT after $24 \mathrm{~h}$ in vitro. In fact, the stimulative effect of insulin on glucose utilization in our study (Chilliard and Faulconnier, 1995) was smaller $(+13 \%)$ than in the study by Vernon and Taylor (1988) $(+100 \%)$, whereas insulin stimulated lactate production in the two studies to a similar extent $(+50 \%)$.

The addition of $100 \mathrm{nM}$ DEX to the incubation medium decreased lactate production, especially in sheep AT $(-68 \%)$, during the first 5 days of incubation. This is consistent with the fact that DEX also decreased glucose utilization by sheep and cow AT explants under the same experimental conditions (Chilliard and Faulconnier, 1995). 
An inhibitory effect of DEX on glucose utilization was also noted to be greater in sheep than in cow AT explants during the first 2 days of incubation (Chilliard and Faulconnier, 1995). These results agree with those of Plested et al (1987) and Vernon and Taylor (1988) who reported that DEX (10 or $100 \mathrm{nM}$ ) decreased lactate production and glucose utilization in sheep AT explants after 24 or $48 \mathrm{~h}$ in vitro. We are not aware of any report on the effect of DEX on lactate production by cow AT.

The addition of $100 \mathrm{nM}$ DEX to the insulin-supplemented medium $(2 \mathrm{mU} / \mathrm{mL})$ did not change lactate production in sheep and cow AT during the first 2 or 3 days of incubation. This is consistent with the fact that it had no effect on glucose utilization in these two species under the same experimental conditions (Chilliard and Faulconnier, 1995). It contrasts, however, with the results of Plested et al (1987) who reported that a DEX addition at a lower concentration $(10 \mathrm{nM})$ to an insulin-supplemented medium $(2.5 \mathrm{mU} / \mathrm{mL})$ decreased the lactate production and glucose utilization by subcutaneous sheep AT after $48 \mathrm{~h}$ of incubation. From days 3 or 4 to 7, DEX addition to an insulinsupplemented medium significantly increased lactate production by cow AT and more markedly by sheep AT. This agrees with the fact that it increased glucose utilization by sheep AT but not by cow AT (Chilliard and Faulconnier, 1995). It may be that in cow AT, the DEX may change the partition of glucose between lactate, acylglycerol glycerol synthesis, $\mathrm{CO}_{2}$ production, or nucleic acid synthesis. As a consequence, DEX addition to an insulin-supplemented medium increased more lactate production by cow AT (fig 1) than glucose utilization (Chilliard and Faulconnier, 1995), thus increasing the LP/GU (fig 2) after 3 days of incubation.

In conclusion, this study showed that lactate production, and LP/GU were higher in sheep than in cow AT during extended incu- bation, and that insulin increased the lactate production in sheep and cow AT, whatever the incubation period. However, the effect of DEX addition to the insulin-supplemented medium differed with incubation time. The lactate production was more related to glucose than to acetate utilization. However, the variations in lactate production were not always similar to those observed for glucose utilization, suggesting that insulin and DEX may change metabolic pathways other than glycolysis. Additional in vitro studies on other products of glucose metabolism are needed to better understand these effects and the variations between species in glucose utilization.

\section{ACKNOWLEDGMENTS}

We thank A Ollier and JP Pezant for the management of animals, G Cuylle for the management of the slaughterhouse, $R$ Lefaivre and $M$ Tourret for technical assistance, C Durier for advice in statistical analysis, and P Béraud for help in preparing the manuscript. This program was supported in part by the Action Incentive Program : Lipogenesis in species of zootechnic interest (Inra).

\section{REFERENCES}

Chilliard Y, Faulconnier Y (1995) Insulin and(or) dexamethasone regulation of glucose and acetate utilization in ovine and bovine adipose tissue explants incubated for seven days. J Anim Sci 73, 2063-2070

Chilliard Y, Gagliostro G, Fléchet J, Lefaivre J, Sebastian I (1991) Duodenal rapeseed oil infusion in early and midlactation cows. 5. Milk fatty acids and adipose tissue lipogenic activities. $J$ Dairy $S c i$ $74,1844-1854$

Faulconnier Y, Thévenet M, Fléchet J, Chilliard Y (1994) Lipoprotein lipase and metabolic activities in incubated bovine adipose tissue explants: effects of insulin, dexamethasone and fetal bovine serum. JAnim Sci 72, 184-191

Faulconnier Y, Guillon L, Chilliard Y (1996) Lipoprotein lipase and glucose-6-phosphate deshydrogenase activities in bovine and ovine adipose tissue incubated for 7 days: effects of insulin and/or dexamethasone. Comp Biochem Physiol 113B, 421426 
Fried SK, Lavau M, Pi-Sunyer X (1982) Variations in glucose metabolism by fat cells from three adipose depots of the rat. Metabolism 31, 876-883

Grandall DL, Fried SK, Francedese AA, Nickel M, DiGirolamo M (1983) Lactate release from isolated rat adipocytes: influence of cell size, glucose concentration, insulin and epinephrine. Horm Metabol Res 15, 326-329

Institut National de la Recherche Agronomique (Inra) (1989) Ruminant Nutrition. Recommended Allowances and Feed Tables (R Jarrige, ed), John Libley Eurotext, Paris, France

Khachadurian AK, Adrouni B, Yacoubian H (1966) Metabolism of adipose tissue in the fat tail of the sheep in vivo. $J$ Lipid Res 7, 427-436

Khachadurian AK, Kamelian M, Adrouni B (1967) Metabolism of sheep adipose tissue in vitro. $\mathrm{Am} \mathrm{J}$ Physio 213, 1385-1390

Newby FD, Sykes MN, DiGirolamo M (1988) Regional differences in adipocyte lactate production from glucose. Am J Physiol 255, E716-E722

Newby FD, Wilson LK, Thacker SV, DiGirolamo M (1990) Adipocyte lactate production remains elevated during refeeding after fasting. Am J Physiol 259, E865-E871

Plested CP, Taylor E, Brindley DN, Vernon RG (1987) Interactions of insulin and dexamethasone in the control of pyruvate kinase activity and glucose metabolism in sheep adipose tissue. Biochem $J 247$, $459-465$

Robertson JP, Faulkner A, Vernon RG (1982) Regulation of glycolysis and fatty acid synthesis from glucose in sheep adipose tissue. Biochem $J 206$, $577-586$

SAS (1987) Guide for Personal Computers (Version 6) SAS Inst Inc Cary, NC, USA
Sebastian I, Chilliard Y, Purroy A, Jaime C (1993) Supplémentation en céréales, état corporel et enzymes lipogéniques du tissu adipeux chez la brebis Aragonesa. Ann Zootech 42, 299-313

Shimojo N, Naka K, Nakajima C, Yoshikawa C, Okuda K, Okada K (1989) Test-strip method for measuring lactate in whole blood. Clin Chem 35, 19921994

Smith SB (1983) Contribution of the pentose cycle to lipogenesis in bovine adipose tissue. Arch Biochem Biophys 221, 46-56

Smith SB, Prior RL (1982) The effect of 3-mercaptopicolinic acid and substrate interactions on the incorporation of lipogenic precursors into glyceride-glycerol, glyceride-fatty acids and nonesterified fatty acids in bovine adipose tissue. Biochem Biophys Acta 712, 365-373

Smith SB, Prior RL (1986) Comparisons of lipogenesis and glucose metabolism between ovine and bovine adipose tissue. $J$ Nutr 116, 1279-1286

Snedecor GW, Cochran WG (1967) Statistical Methods (6th Ed), Iowa State University Press, Iowa, USA, 91-119

Thacker SV, Nickel M, DiGirolamo M (1987) Effects of food restriction on lactate production from glucose by rat adipocytes. Am J Physiol 253, E336E342

Vernon RG (1980) Lipid metabolism in the adipose tissue of ruminant animals. Prog Lipid Res 19, 23106

Vernon RG, Taylor E (1988) Insulin, dexamethasone and their interactions in the control of glucose metabolism in adipose tissue from lactating and non-lactating sheep. Biochem J 256, 509-514

Winer BJ (1971) Statistical Principles in Experimental Design. McGraw-Hill Publishing Co, New York, USA 